\title{
Correction to: Pulse waveform analysis of optic nerve head circulation for predicting carotid atherosclerotic changes
}

\author{
Rina Muramatsu ${ }^{1} \cdot$ Tomoaki Shiba $^{2} \cdot$ Mao Takahashi $^{3} \cdot$ Yuichi Hori $^{2} \cdot$ Takatoshi Maeno $^{1}$
}

Published online: 26 October 2021

○) Springer-Verlag GmbH Germany, part of Springer Nature 2021

\section{Correction to: Graefes Arch Clin Exp Ophthalmol (2015) 253:2285-2291} https://doi.org/10.1007/s00417-015-3123-y

In the original published article, the name of the first author has been captured incorrectly.

"Muramatsu Rina" should be "Rina Muramatsu".

Publisher's note Springer Nature remains neutral with regard to jurisdictional claims in published maps and institutional affiliations.

The online version of the original article can be found at https:// doi.org/10.1007/s00417-015-3123-y

Tomoaki Shiba

tomoaki-s@med.toho-u.ac.jp

1 Department of Ophthalmology, Toho University Sakura

Medical Center, Chiba, Japan

2 Department of Ophthalmology, School of Medicine Toho University, 6-11-1, Omori-Nishi, Ota-ku, Tokyo 143-8541, Japan

3 Cardiovascular Center, Toho University Sakura Medical Center, Chiba, Japan 